\title{
Psychotropic Medication After Intensive Care Unit-Treated Pediatric Traumatic Brain Injury
}

\section{Mikkonen, Era D.}

2020-11

Mikkonen , E D , Skrifvars , M B , Reinikainen , M , Bendel , S , Laitio , R , Hoppu , S , Ala-Kokko , T , Karppinen , A \& Raj , R 2020 , ' Psychotropic Medication After Intensive Care Unit-Treated Pediatric Traumatic Brain Injury ' , Pediatric Neurology , vol. 112 , pp. 64-70 . https://doi.org/10.1016/j.p

http://hdl.handle.net/10138/334093

https://doi.org/10.1016/j.pediatrneurol.2020.05.002

cc_by_nc_nd

acceptedVersion

Downloaded from Helda, University of Helsinki institutional repository.

This is an electronic reprint of the original article.

This reprint may differ from the original in pagination and typographic detail.

Please cite the original version. 


\section{Journal Pre-proof}

Psychotropic medication after intensive care unit treated pediatric traumatic brain injury

Era D. Mikkonen, MD, Markus B. Skrifvars, MD, PhD, Matti Reinikainen, MD, PhD, Stepani Bendel, MD, PhD, Ruut Laitio, MD, PhD, Sanna Hoppu, MD, PhD, Tero AlaKokko, MD, PhD, Atte Karppinen, MD, PhD, Rahul Raj, MD, PhD

PII: S0887-8994(20)30152-1

DOI: https://doi.org/10.1016/j.pediatrneurol.2020.05.002

Reference: PNU 9781

To appear in: Pediatric Neurology

Received Date: 12 December 2019

Revised Date: 27 April 2020

Accepted Date: 2 May 2020

Please cite this article as: Mikkonen ED, Skrifvars MB, Reinikainen M, Bendel S, Laitio R, Hoppu S, Ala-Kokko T, Karppinen A, Raj R, Psychotropic medication after intensive care unit treated pediatric traumatic brain injury, Pediatric Neurology (2020), doi: https://doi.org/10.1016/ j.pediatrneurol.2020.05.002.

This is a PDF file of an article that has undergone enhancements after acceptance, such as the addition of a cover page and metadata, and formatting for readability, but it is not yet the definitive version of record. This version will undergo additional copyediting, typesetting and review before it is published in its final form, but we are providing this version to give early visibility of the article. Please note that, during the production process, errors may be discovered which could affect the content, and all legal disclaimers that apply to the journal pertain.

(c) 2020 Elsevier Inc. All rights reserved. 


\section{Psychotropic medication after intensive care unit treated pediatric traumatic brain injury}

Era D. Mikkonen*, MD ${ }^{1}$, Markus B. Skrifvars, MD, $\mathrm{PhD}^{2}$, Matti Reinikainen, $\mathrm{MD}, \mathrm{PhD}^{3}$, Stepani Bendel, MD, $\mathrm{PhD}^{3}$, Ruut Laitio, MD, PhD ${ }^{4}$, Sanna Hoppu, MD, PhD ${ }^{5}$, Tero AlaKokko, MD, $\mathrm{PhD}^{6}$, Atte Karppinen, $\mathrm{MD}, \mathrm{PhD}^{7}$, Rahul Raj, MD, $\mathrm{PhD}^{7}$

1. Department of Anesthesiology, Intensive Care and Pain Medicine and Department of Emergency Care and Services, Helsinki University Hospital \& University of Helsinki, Helsinki, Finland

2. Department of Emergency Care and Services, Helsinki University Hospital \& University of Helsinki, Helsinki, Finland

3. Department of Anesthesiology and Intensive Care, Kuopio University Hospital \& University of Eastern Finland, Kuopio, Finland

4. Department of Intensive Care, Turku University hospital \& University of Turku, Turku, Finland

5. Emergency Medical Services and Department of Intensive Care, Tampere University Hospital \& Tampere University, Tampere, Finland

6. Division of Intensive Care, Medical Research Center Oulu MRC, Oulu University Hospital, Research group of Anesthesiology, Surgery and Intensive Care Medicine, University of Oulu, Oulu, Finland

7. Department of Neurosurgery, Helsinki University Hospital and University of Helsinki, Helsinki, Finland

\section{${ }^{*}$ Corresponding author information:}

- E-mail: era.mikkonen@helsinki.fi

- Address: Holländargatan 31, Stockholm 11359, Sweden

- Telephone: +358503702373

\section{Sources of Funding and Conflict of Interest:}

- Era Mikkonen: No separate funding. No conflicts of interest.

- Markus Skrifvars: Independent funding from University of Helsinki, Helsinki University Hospital, Medicinska Understödsföreningen Liv \& Hälsa, Dorothea Olivia, Karl Walter och Jarl Walter Perklens stiftelse. No conflicts of interest.

- Matti Reinikainen: No separate funding. No conflicts of interest.

- Stepani Bendel: No separate funding. No conflicts of interest.

- Ruut Laitio: No separate funding. No conflicts of interest.

- Sanna Hoppu: Competitive State Research Financing of Tampere University Hospital. No conflicts of interest.

- Tero Ala-Kokko: No separate funding. No conflicts of interest.

- Atte Karppinen: No separate funding. No conflicts of interest.

- Rahul Raj: Independent funding from Medicinska Understödsföreningen Liv \& Hälsa, Finska Läkaresällskapet, Svenska Kulturfonden, Helsinki University Hospital research grant. No conflicts of interest. 
This research did not receive any specific grant from funding agencies in the public, commercial, or not-for-profit sectors.

Abstract word count: 256

Text word count: 2,882

Reference numbers: 34

Number of tables and figures: 5 tables, 1 figure

Supplemental digital content: 8 


\section{Abstract}

Objective: Our aim was to assess occurrence and risk factors for psychotropic medication use after pediatric traumatic brain injury (TBI) treated in the intensive care unit (ICU). Study population: Children aged 5-17 years treated due to a TBI in four university hospitals ICUs in Finland during 2003-2013 and being alive six months after injury with no history of psychotropic medication use prior to TBI.

Measurements and Main Results: We combined data from the Finnish Intensive Care Consortium database, data on reimbursed medications from the Social Insurance Institute and individual electronic health care data. We identified 248 patients of whom $46(19 \%)$ were prescribed a new psychotropic medication after TBI. In multivariable logistic regression, a higher age associated with a higher probability for use of any psychotropic medication. Subgroup analyses showed that higher age associated with an increased risk of antidepressant use and antipsychotic use but with a decreased risk of stimulant use. Apart from age, we found no other clinical, radiological or treatment-related factors that significantly associated with subsequent use of psychotropics. Psychotropic medication was most common (45\%) in children who were aged $12-17$ years and had moderate disability at six-month follow up.

Conclusion: One fifth of children treated in the ICU for TBI were prescribed a new psychotropic medication during a median follow-up of 3 years and 5 months. Psychotropic medication was most common among teenagers with moderate posttraumatic disability. The need and use of psychotropics post injury seem multifactorial and not related to any TBI injury type.

Key words: Child, Adolescent, Traumatic Brain Injury, Psychoactive Agents, Population at Risk, Intensive Care Units 


\section{Introduction}

\section{Background}

Traumatic brain injury (TBI) can cause a vast array of neurological, psychological and social sequelae, ranging from motor disability to severely impaired social functions. There are several risk factors for impaired mental wellbeing following TBI. Psychiatric vulnerability and environmental factors before and after injury seem to play an important role in the psychiatric morbidity after TBI [1-7]. Intensive treatment measures and long hospital stays can also cause psychiatric consequences to pediatric TBI survivors [8]. It has also been suggested that the development of depressive symptoms following pediatric TBI is not a primary result of the injured brain, but secondary to other factors associated with TBI [1]. This is supported by the finding that concomitant extracranial limb injury is associated with the likelihood of post-injury mental illness in patients with TBI [9].

There are, however, some known risk factors related to the actual brain injury. Injury severity seems to associate with the risk of developing psychiatric illness $[5,6]$. In pediatric TBI patients, frontal lobe lesions seem to associate with depression, anxiety and secondary attention deficit hyperactivity disorder $[5,10,11]$. Structural brain damage is also known to cause organic personality disorder, a heterogenous disorder which can include changes in personality, emotional control and attention [12].

The psychiatric sequelae of TBI are heterogenous and require multiple different treatment approaches. As with pediatric mental distress in general, support to the patient and the family is important, together with psychotherapy and psychotropic medication when needed. There are some efficacy and safety concerns when deciding whether to treat a developing brain with psychotropic medication. This could explain the heterogeneity seen 
globally in the medication with psychotropics in young patients $[13,14]$. However, the use of psychotropics has been increasing both in Finland and the U.S. during the early 21 st century $[15,16]$. The use of antidepressants has risen despite the 2004 FDA caution concerning increased suicide rates [17]. Furthermore, off-label use of antipsychotics in children, especially in neuropsychiatric behavioral problems is not uncommon $[18,19]$.

Pediatric TBI patients requiring intensive care unit (ICU) treatment have multiple risk factors for subsequent psychiatric morbidity and need for psychotropic medication. We aimed to examine these risk factors for subsequent utilization of psychotropic medication in a pediatric TBI population treated in the ICU in four university hospitals in Finland during the years 2003-2013. We hypothesized that factors indicative of injury severity and longer and more intense hospital stays would associate with a higher psychotropic usage in pediatric TBI survivors. 


\section{Materials and Methods}

\section{Study ethics statement}

This study was approved by the local ethical committee of the Helsinki University Hospital (HUS/26/2018 §37), the Finnish National Institute for Health and Welfare (THL/2014/5.05.00/2017), Statistics Finland (TK-53-1047-14) and all of the participating university hospitals' research committees. The need for informed consent was waived. The study adhered to the Strengthening the Reporting of Observational studies in Epidemiology guidelines.

\section{Study setting}

Neurosurgery and neurointensive care are provided only at five university hospitals in Finland. Four of these five neurointensive care units (in the university hospitals of Kuopio, Oulu, Tampere and Turku) participate in the Finnish Intensive Care Consortium (FICC) database that prospectively collects data on ICU patients [20]. Taken together, these four hospitals cover approximately two thirds of the Finnish population. We used the FICC database to identify pediatric TBI patients treated in the ICU at these four centers. Three centers also have separate pediatric ICUs. These are not covered by the FICC database. However, during the study period, all centers admitted pediatric TBI patients requiring neurointensive care to the general ICU.

\section{Study population}

We identified all pediatric (5-17 years of age) TBI patients in the FICC database admitted between the years 2003 to 2013 based on their Acute Physiology and Chronic Health Evaluation (APACHE) III and ICD-10 diagnoses. Due to low prescription frequencies in infants and the size of our study population, we excluded patients aged 0-4 years [16,21]. 
We reviewed their electronic health records and excluded patients with missing admission and follow-up data. We also reviewed all patient's admission computed tomography (CT) scans to verify the TBI diagnosis and to calculate Helsinki CT scores for injury severity assessment [22]. We have previously validated the performance of the Helsinki CT score in pediatric TBI [23]. We excluded foreign patients and patients with penetrating head injury, missing admission CT scans, missing admission or follow up data and patients that died before six months follow up. We excluded patients with pre-existing psychotropic or neurologic prescriptions in order not to confound our study population in the search for injury or treatment related risk factors for post traumatic psychiatric drug prescriptions.

\section{Extracted variables}

We used the FICC database to collect Therapeutic Intervention Scoring System (TISS) 76 scores (a treatment intensity scoring for the ICU), data on anti-epileptic drug use during ICU stay, and length of ICU and hospital stay. From the electronic health records, we collected admission data such as Glasgow Coma Scale (GCS) score, pupillary light reactivity and major extracranial injury [24]. For patients who arrived sedated, we used the GCS score reported prior to sedation. From electronic health records, we also collected data on treatment measures such as surgical interventions and repeated use of barbiturate, as well as outcome data from follow up visits at neurosurgeons, pediatric neurologists and neuropsychologists. From the Social Insurance Institute in Finland (Kela), we retrieved reimbursement data on the patients' prescribed medications before the end of 2013. The Kela database is comprehensive an includes all prescription medications in Finland $[25,26]$. 


\section{Definition of outcome variables}

Our primary outcome was reimbursement of any psychotropic medication (ATC codes N05A-C* or N06A-C*, excluding N06D [anti-dementia medications] see Supplemental Digital Content 1 for full list of included medications). Our secondary outcomes were

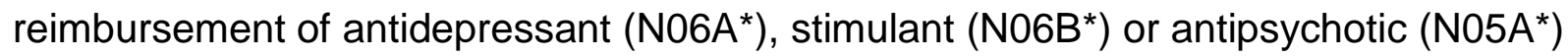
medication separately. We also assessed the association between functional outcome Glasgow Outcome Scale score ([GOS] with age appropriate adjustments [27]) and the use of psychotropic medication.

We obtained data regarding trends in reimbursement of psychotropic medication in the general pediatric population of Finland for all children between 5 and 17 years of age (Supplemental Digital Content 2-5).

\section{Statistical analyses}

For the statistical analyses, we used Stata (version 15, StataCorp, College Station, TX) and SPSS Statistics 24.0 for mac OS (IBM Corp, Armonk, NY). We compared categorical data using a two-sided $x^{2}$-test. We tested continuous data for skewness and present normally distributed data as means with standard deviations (SD) and non-parametric data as medians with interquartile ranges (IQR). We compared non-parametric data between groups using a non-parametric Mann-Whitney $U$ test and we compared normally distributed data between groups using a t-test.

First, we tested differences in admission variables and treatment-related variables between groups with and without any psychotropic, antidepressant, stimulant and 


\section{Joumal Pre-proof}

antipsychotic medication, respectively. From the univariable analyses, we inserted variables with $p$-values $<0.1$ into multivariable logistic regression (LR) models. We built separate LR models including admission variables only and LR models including admission variables combined with treatment-related variables. We built separate LR models with "any psychotropic medication", "antidepressant medication", "stimulant medication" and "antipsychotic medication" as the outcome. We measured the explanatory power using the Nagelkerke $\mathrm{R}^{2}$ test (ranging from 0 to 1,0 indicating that the model does not explain the outcome and 1 indicating that the model completely explains the outcome). 


\section{Results}

Of 327 patients, 248 were eligible (Figure 1) and enrolled to the study. Totally 33 patients were excluded due to missing data, 22 patients died within six months from injury, 15 were excluded because of pre-existing psychotropic medication and 1 because of pre-existing antiepileptic medication.

Out of 248 patients, 46 patients received some psychotropic medication (Table 1). Median time to medication was 14 months (inter-quartile range [IQR] 5-30) and median age at medication was 17 years (IQR 15-18). Median follow up was 3 years and 5 months.

\section{Characteristics of patients with psychotropic medication}

In the univariate analysis, patients with psychotropic medication were older, had lower admission GCS scores, more often abnormal pupillary light reactions and higher Helsinki CT scores, as compared to patients without psychotropic medication (Table 1). Treatment for acute seizures in the ICU, intracranial pressure (ICP) monitoring and external ventricular drains and repeated use of barbiturates were more common in patients with psychotropic medication. Moreover, patients with psychotropic medication had higher intensity of care, reflected by TISS-76 scores, and longer lengths of ICU stay. In the multivariable LR analysis of admission variables, only age was associated with an increased risk of post-TBI psychotropic medication (Table 2). When treatment-related variables were added to the multivariable prediction model, age was no longer an independent predictor of post-TBI psychotropic medication (Table 3). The explanatory power (Nagelkerke $R^{2}$ ) was 0.112 for the LR model with admission variables only and 0.184 for the LR model including treatment-related variables. 


\section{Subgroup analyses}

The results from the univariable analyses according to antidepressant medication, stimulant medication and antipsychotic medication are shown in the Supplemental Digital Content 6-8. Patients with antidepressant medication were older, had lower GCS scores and more often presented abnormal pupillary light reactivity. Patients with stimulant medication were younger and patients with antipsychotic medication were older than those without medication. There were no differences in GCS score or pupillary light reactivity in patients with stimulant or antipsychotic medication. In the multivariable LR analysis (Table 4), only age associated with an increased risk of antidepressant usage (odds ratio (OR) 1.4 for each year of age, 95\% confidence interval (Cl) 1.2-1.7). Higher age was associated with a lower risk of stimulant use (OR 0.8 for each year of age, $95 \% \mathrm{Cl} 0.6$ 0.9). On the contrary, higher age was associated with an increased risk of antipsychotic medication (OR 1.2 for each year of age, $95 \% \mathrm{Cl} 1.0-1.5)$ for usage. The explanatory power was low for all LR models (Nagelkerke $R^{2}$ between 0.096 and 0.363 ).

\section{Functional outcome and psychotropic medication}

Functional outcome was associated with psychotropic medication in all univariable analyses except for stimulant medication (Supplemental Digital Content 6-8). Patients with moderate disability at follow up (GOS 4) were most likely to have a psychotropic medication (8-31\% of patients). Medication was most common for patients who were aged over 12 years at the time of injury and later suffered from moderate disability: $45 \%$ used some psychotropic medication, $36 \%$ used antidepressants and $24 \%$ used antipsychotics (Table 5). Medication was less common for patients aged 5-11 years at the time of injury, and the figures were less consistent across outcome categories. 


\section{Discussion}

In this retrospective observational analysis of patients aged 5-17 years treated in the ICU for TBI, we found high rates of psychotropic medication in adolescents with moderate disability. Apart from age, we found no statistically significant predictors of subsequent psychotropic medication, and all multivariable models showed very poor explanatory power. This suggests that the need and use of psychotropic medications post injury are, as expected, multifactorial and not specifically related to any TBI injury type.

According to national data on reimbursement frequencies in the general pediatric population of Finland during the study period, on average $1,7 \%$ of 5 -17-year-olds received a psychotropic prescription each year $[0.6 \%$ received antidepressants, $1 \%$ stimulants and 0.5\% antipsychotics (Supplemental Digital Content 2-5 showing temporal trends in reimbursed psychiatric medications in the general pediatric population over the study years)]. There are large international differences in prescriptions trends of psychotropic medications to children and adolescents [28]. Finland has low prescription rates compared to other Nordic countries, especially concerning stimulant use. Prescription frequencies correlate well with the number of diagnoses, suggesting that the low prescription rates of stimulants are not related to drug availability but rather a matter of diagnosis. There is also large regional differences within Finland, and the difference in the utilization rates of stimulant drugs between sexes is higher in Finland compared to the other Nordic countries. $[17,28-30]$.

In our cohort, higher age increased the probability of medication in all classes except stimulants, where the relationship was inverse. According to the national data, 12-17-year- 
old adolescents used psychotropic medications, except stimulants, more commonly than younger children. In the beginning of the study period, children aged 5-11 had higher rates of stimulant usage, later to be surpassed by adolescents. Higher rates of stimulant medication in younger patients was found by a national study conducted in 2009 [16]. Thus, we interpret the findings in our cohort to be a result of general medication trends in Finland, not related to an age-dependent neurobiological response to TBI.

Historically, there has been a reluctance towards pharmacotherapy in pediatric psychiatry, yet today, some suggest that the rate of pharmacotherapy is alarmingly high [31]. The evidence on long term effects on the developing brain is still insufficient and there is a concern of overdiagnosis in children and youth [32]. Furthermore, many off-label pharmacological practices lack studies in pediatric patients and the data is extrapolated from the adult population [33]. We were surprised to find the high rate of medication use in adolescents with moderate disability, especially concerning antipsychotics that were used by a quarter of patients. In the United States, antipsychotics are frequently prescribed off-label to children and adolescents with behavioral problems $[18,19]$. Several reasons have been suggested: proven efficacy of antipsychotics in treatment of child and adolescent aggression in psychiatric disease, limited access and affordability of non-pharmacologic treatment and inadequate provider time [19]. Similar trends in Finland could explain our findings.

Interestingly, none of the patients in our study were reimbursed for melatonin. This should be contrasted to the fact, that melatonin was a prescription only drug up until the year of 2013. Thus, prescribed melatonin should have been captured by our study. 
Previous literature has observed an association between TBI severity and psychiatric morbidity. However, we did not observe any clear relationship between injury severity and use of psychotropic medication. As suggested in the review by Durish [1], depressive symptoms might develop secondary to other TBI sequelae. This is supported by our data, which shows high frequencies of psychotropic medication in patients with moderate disability after TBI but fails to show any association with clinical admission variables apart from age. This suggests that the risk of severe psychiatric morbidity is more closely related to general functional outcomes than to injury specific clinical variables.

Our study has several strengths. Our dataset is relatively large for ICU-treated pediatric $\mathrm{TBI}$, and the follow up was good at almost three and a half years. The quality of the data is high for a retrospective analysis. First, all patients' electronic health records were assessed individually, including all patients' CT scans. Secondly, high-quality data on psychotropic reimbursement were obtained from the Kela database, which includes data on all reimbursed medications in Finland.

The psychiatric sequelae after TBI have unique characteristics including general difficulties with emotional control, attention and anxiety, often accompanied by personality change [7]. There is little evidence on the efficacy of psychopharmacological treatments in this understudied group of patients [33]. Thus, we think our study highlights a significant knowledge gap in the field of pediatric neurorehabilitation.

There are some limitations that need to be mentioned. We had limited information on preinjury morbidity and environmental factors. Pre-injury psychiatric problems, 
environmental factors and parental mental illness seems to increase the risk of pediatric TBI, possibly by increasing high risk behavior [7,34]. In addition, pre-injury psychosocial adversity seems to increase the risk of psychiatric problems after TBI [3]. We did not have access to data on parental morbidity or other environmental factors such as parental socioeconomic status. Furthermore, medication data are a crude measure of psychiatric morbidity, and with only pre-TBI psychotropic medication as a marker of pre-injury mental health problems we do have a risk of reverse causality in our analysis. However, because of the patients living in different regions in the country we were unable to access health records from other time periods than the university hospital treatment episodes, and we therefore had to rely on Kela drug reimbursement databases to cover the entire population. The Kela drug reimbursement database has been described before and is of high quality [26].

Clonidine is an FDA approved treatment for ADHD and may be used in children and adolescents as well. We did, however, not consider Clonidine as it does not belong to the ATC N05 or N06 drug classes. We excluded dementia drugs (ATC N06D) from our study, as the use of these drugs in the general pediatric population ( $<18$ years) was virtually non-existent during the study years (Kela data).

As three out of four centers included in the study also had pediatric ICUs admitting TBI patients not in the need for neurointensive care, some hospitalized TBI cases of mild to moderate severity might have been missed by our study.

We did not differentiate between different locations of cerebral contusion. Thus, we were unable to take into account the role of e.g. frontal lobe lesions in our analysis. Also, GOS 
at six months from injury was assessed based on patient medical records, making the differentiation of GOS classes four and five (moderate disability to no disability) difficult and prone to inaccuracies unless specifically mentioned in the records. Furthermore, GOS is a crude measure of outcome. 


\section{Conclusions}

Psychotropic medication is common among children who have suffered an ICU-treated TBI. No specific injury related factors were independent predictors of psychotropic medication, which supports a multifactorial nature of post TBI psychiatric morbidity. The incidence of psychotropic medication was especially high in teenagers with moderate posttraumatic disability. 


\section{Acknowledgements}

We would like to thank the research staff at the respective university hospitals ICUs for their help with the data collection. 


\section{References}

[1] Laliberté Durish C, Pereverseff RS, Yeates KO. Depression and Depressive Symptoms in Pediatric Traumatic Brain Injury: A Scoping Review. J Head Trauma Rehabil 2018;33:E18-30. https://doi.org/10.1097/HTR.0000000000000343.

[2] Narad ME, Kennelly M, Zhang N, Wade SL, Yeates KO, Taylor HG, et al. Secondary Attention-Deficit/Hyperactivity Disorder in Children and Adolescents 5 to 10 Years After Traumatic Brain Injury. JAMA Pediatr 2018;172:437. https://doi.org/10.1001/jamapediatrics.2017.5746.

[3] GERRING JP, BRADY KD, CHEN A, VASA R, GRADOS M, BANDEEN-ROCHE KJ, et al. Premorbid Prevalence of ADHD and Development of Secondary ADHD After Closed Head Injury. J Am Acad Child Adolesc Psychiatry 1998;37:647-54. https://doi.org/10.1097/00004583-199806000-00015.

[4] VASA RA, GERRING JP, GRADOS M, SLOMINE B, CHRISTENSEN JR, RISING W, et al. Anxiety After Severe Pediatric Closed Head Injury. J Am Acad Child Adolesc Psychiatry 2002;41:148-56. https://doi.org/10.1097/00004583-20020200000008.

[5] Brown G, Chadwick O, Shaffer D, Rutter M, Traub M. A prospective study of children with head injuries: III. Psychiatric sequelae. Psychol Med 1981;11:63-78. https://doi.org/10.1017/s0033291700053289.

[6] MAX JE, ROBIN DA, LINDGREN SD, SMITH WL, SATO Y, MATTHEIS PJ, et al. Traumatic Brain Injury in Children and Adolescents: Psychiatric Disorders at Two Years. J Am Acad Child Adolesc Psychiatry 1997;36:1278-85. https://doi.org/10.1097/00004583-199709000-00021.

[7] Schachar RJ, Park LS, Dennis M. Mental Health Implications of Traumatic Brain Injury (TBI) in Children and Youth. J Can Acad Child Adolesc Psychiatry 2015;24:100-8.

[8] Davydow DS, Richardson LP, Zatzick DF, Katon WJ. Psychiatric morbidity in pediatric critical illness survivors: a comprehensive review of the literature. Arch Pediatr Adolesc Med 2010;164:377-85.

https://doi.org/10.1001/archpediatrics.2010.10.

[9] Alway Y, Gould KR, Johnston L, McKenzie D, Ponsford J. A prospective examination of Axis I psychiatric disorders in the first 5 years following moderate to severe traumatic brain injury. Psychol Med 2016;46:1331-41. https://doi.org/10.1017/S0033291715002986.

[10] Jeffrey E. Max MBBC, Eva Keatley BS, Elisabeth A. Wilde PD, Erin D. Bigler PD, Harvey S. Levin PD, Russell J. Schachar MD, et al. Anxiety Disorders in Children and Adolescents in the First Six Months After Traumatic Brain Injury. J Neuropsychiatry Clin Neurosci 2011;23:29-39. 
[11] Max JE, Wilde EA, Bigler ED, Thompson WK, MacLeod M, Vasquez AC, et al. Neuroimaging correlates of novel psychiatric disorders after pediatric traumatic brain injury. J Am Acad Child Adolesc Psychiatry 2012;51:1208-17.

https://doi.org/10.1016/j.jaac.2012.08.026.

[12] World Health Organization. The ICD-10 Classification of Mental and Behavioural Disorders. n.d.

[13] Vitiello B. Research in child and adolescent psychopharmacology: recent accomplishments and new challenges. Psychopharmacology (Berl) 2007;191:5-13. https://doi.org/10.1007/s00213-006-0414-3.

[14] McVoy M, Findling R. Child and Adolescent Psychopharmacology Update. Psychiatr Clin North Am 2009;32:111-33. https://doi.org/10.1016/j.psc.2008.11.002.

[15] Olfson M, Blanco C, Wang S, Laje G, Correll CU. National Trends in the Mental Health Care of Children, Adolescents, and Adults by Office-Based Physicians. JAMA Psychiatry 2014;71:81. https://doi.org/10.1001/jamapsychiatry.2013.3074.

[16] Ilona Autti-Rämö, Johanna Seppänen, Raimo Raitasalo, Jaana E. Martikainen AS. Increase in the use of psychotropics among adolescents and young adults since the beginning of the 21st century. Lääkärilehti 2009:477-82.

[17] Autti-Rämö I, Sourander A, Seppänen J, Martikainen JE. Use of antidepressants among 0-26 year olds in Finland during 1997-2007. Eur J Psychiatry 2011;25:16472. https://doi.org/10.4321/S0213-61632011000300006.

[18] Alexander GC, Gallagher SA, Mascola A, Moloney RM, Stafford RS. Increasing offlabel use of antipsychotic medications in the United States, 1995-2008.

Pharmacoepidemiol Drug Saf 2011;20:177-84. https://doi.org/10.1002/pds.2082.

[19] Harrison JN, Cluxton-Keller F, Gross D. Antipsychotic medication prescribing trends in children and adolescents. J Pediatr Health Care 2012;26:139-45. https://doi.org/10.1016/j.pedhc.2011.10.009.

[20] Reinikainen M, Mussalo P, Hovilehto S, Uusaro A, Varpula T, Kari A, et al. Association of automated data collection and data completeness with outcomes of intensive care. A new customised model for outcome prediction. Acta Anaesthesiol Scand 2012;56:1114-22. https://doi.org/10.1111/j.1399-6576.2012.02669.x.

[21] Sultan RS, Correll CU, Schoenbaum M, King M, Walkup JT, Olfson M. National patterns of commonly prescribed psychotropic medications to young people. J Child Adolesc Psychopharmacol 2018;28:158-65. https://doi.org/10.1089/cap.2017.0077.

[22] Raj R, Siironen J, Skrifvars MB, Hernesniemi J, Kivisaari R. Predicting Outcome in Traumatic Brain Injury. Neurosurgery 2014;75:632-47. https://doi.org/10.1227/NEU.0000000000000533.

[23] Mikkonen ED, Skrifvars MB, Reinikainen M, Bendel S, Laitio R, Hoppu S, et al. Validation of prognostic models in intensive care unit-treated pediatric traumatic brain injury patients. J Neurosurg Pediatr 2019:1-8. https://doi.org/10.3171/2019.4.PEDS1983. 
[24] MRC CRASH Trial Collaborators MCT, Perel P, Arango M, Clayton T, Edwards P, Komolafe E, et al. Predicting outcome after traumatic brain injury: practical prognostic models based on large cohort of international patients. BMJ 2008;336:425-9. https://doi.org/10.1136/bmj.39461.643438.25.

[25] Furu K, Wettermark B, Andersen M, Martikainen JE, Almarsdottir AB, Sørensen HT. The Nordic Countries as a Cohort for Pharmacoepidemiological Research. Basic Clin Pharmacol Toxicol 2010;106:86-94. https://doi.org/10.1111/j.17427843.2009.00494.x.

[26] Saarinen MM, Sillanpää M, Schmidt D, Virta LJ. Long-term changes in the incidence of childhood epilepsy. A population study from Finland. Epilepsy Behav 2016;58:815. https://doi.org/10.1016/J.YEBEH.2016.02.040.

[27] Young AMH, Guilfoyle MR, Fernandes H, Garnett MR, Agrawal S, Hutchinson PJ. The application of adult traumatic brain injury models in a pediatric cohort. $J$ Neurosurg Pediatr 2016;18:558-64. https://doi.org/10.3171/2016.5.PEDS15427.

[28] Steinhausen HC. Recent international trends in psychotropic medication prescriptions for children and adolescents. Eur Child Adolesc Psychiatry 2015;24:635-40. https://doi.org/10.1007/s00787-014-0631-y.

[29] Vuori M, Aronen E, Sourander A, Martikainen JE, Jantunen T, Saastamoinen L. Prescribed stimulant use for ADHD rises steadily. Duodecim 2018;134:1515-37.

[30] Furu K, Karlstad Ø, Zoega H, Martikainen JE, Bahmanyar S, Kieler H, et al. Utilization of Stimulants and Atomoxetine for Attention-Deficit/Hyperactivity Disorder among 5.4 Million Children Using Population-Based Longitudinal Data. Basic Clin Pharmacol Toxicol 2017;120:373-9. https://doi.org/10.1111/bcpt.12724.

[31] Rapoport JL. Pediatric psychopharmacology: Too much or too little? World Psychiatry 2013;12:118-23. https://doi.org/10.1002/wps.20028.

[32] Giles LL, Martini DR. Challenges and Promises of Pediatric Psychopharmacology. Acad Pediatr 2016;16:508-18. https://doi.org/10.1016/j.acap.2016.03.011.

[33] Pangilinan PH, Giacoletti-Argento A, Shellhaas R, Hurvitz EA, Hornyak JE. Neuropharmacology in Pediatric Brain Injury: A Review. PM R 2010;2:1127-40. https://doi.org/10.1016/j.pmrj.2010.07.007.

[34] Lowery Wilson M, Tenovuo O, Gissler M, Saarijärvi S. Association between parent mental health and paediatric TBI: epidemiological observations from the 1987 Finnish Birth Cohort. Inj Prev 2019;25:283-9. https://doi.org/10.1136/injuryprev2017-042624. 


\section{Figure Legends:}

Figure 1: Flow chart. Abbreviations: TBI, Traumatic Brain Injury; FICC, Finnish Intensive Care Consortium; GCS, Glasgow Coma Scale; CT, Computer Tomography.

\section{Supplemental Digital Content:}




\section{Journal Pre-proo}

Supplemental Digital Content 1. List of included ATC codes and generic names of respective drugs

Supplemental Digital Content 2: Reimbursement frequencies in the general pediatric population of any psychotropic medication, ages 5-17 years, from 2003-2013

Supplemental Digital Content 3: Antidepressant reimbursement frequencies in the general pediatric population, ages 5-17 years, from 2003-2013

Supplemental Digital Content 4: Stimulant reimbursement frequencies in the general pediatric population, ages 5-17 years, from 2003-2013

Electronic supplementary 5: Antipsychotic reimbursement frequencies in the general pediatric population, ages 5-17 years, from 2003-2013

Supplemental Digital Content 6: Patient characteristics, antidepressant medication Supplemental Digital Content 7: Patient characteristics, stimulant medication Supplemental Digital Content 8: Patient characteristics, antipsychotic medication 
Table 1: Patient characteristics, any psychiatric prescription

\begin{tabular}{|c|c|c|c|c|}
\hline Admission variables & All $(\mathrm{N}=248)$ & $\begin{array}{l}\text { Medication } \\
(\mathrm{N}=46)\end{array}$ & $\begin{array}{l}\text { No medication } \\
(\mathrm{N}=202)\end{array}$ & P-Value \\
\hline Age, median (IQR) & $15(11-16)$ & $16(15-17)$ & $15(10-16)$ & 0.004 \\
\hline $5-11$ & $78(32 \%)$ & $8(17 \%)$ & $70(35 \%)$ & 0.02 \\
\hline $12-17$ & $170(69 \%)$ & $38(83 \%)$ & $132(65 \%)$ & \\
\hline Females & $71(29 \%)$ & $12(26 \%)$ & $59(29 \%)$ & 0.67 \\
\hline GCS score, median (IQR) & $11(6-14)$ & $7(5-13)$ & $11(7-14)$ & 0.001 \\
\hline $3-8$ & $96(39 \%)$ & $27(59 \%)$ & $69(34 \%)$ & 0.008 \\
\hline $9-12$ & $52(21 \%)$ & $7(15 \%)$ & $45(22 \%)$ & \\
\hline $13-15$ & $100(40 \%)$ & $12(26 \%)$ & 88 (44\%) & \\
\hline \multicolumn{5}{|l|}{ Pupillary light reactivity } \\
\hline Both react & $216(87 \%)$ & $34(74 \%)$ & $182(90 \%)$ & 0.01 \\
\hline One reacts & $23(9 \%)$ & $8(17 \%)$ & $15(7 \%)$ & \\
\hline None react & $9(4 \%)$ & $4(9 \%)$ & $5(3 \%)$ & \\
\hline Major extracranial injury & $102(41 \%)$ & $23(50 \%)$ & 79 (39\%) & 0.18 \\
\hline Helsinki CT score & $2(0-4)$ & $2(2-5)$ & $2(0-4)$ & 0.04 \\
\hline \multicolumn{5}{|l|}{ Treatment-related variables } \\
\hline Rx of new seizure in the ICU & $50(20 \%)$ & $17(37 \%)$ & $33(16 \%)$ & 0.002 \\
\hline Craniotomy or craniectomy & $63(25 \%)$ & $13(28 \%)$ & $50(25 \%)$ & 0.62 \\
\hline $\begin{array}{l}\text { Parenchymal ICP monitoring or } \\
\text { EVD }\end{array}$ & $88(36 \%)$ & $24(52 \%)$ & $64(32 \%)$ & 0.009 \\
\hline Repeated use of barbiturates & $23(9 \%)$ & $8(17 \%)$ & $15(7 \%)$ & 0.04 \\
\hline TISS-76 mean per day (median, IQR) & $25(19-35)$ & $30(23-38)$ & $23(18-33)$ & 0.003 \\
\hline TISS-76 total (median, IQR) & $64(39-322)$ & $215(51-591)$ & $55(36-277)$ & $<0.001$ \\
\hline LOS ICU, (median, IQR) & $2(1-8)$ & $6(1-14)$ & $2(1-7)$ & $<0.001$ \\
\hline LOS hospital, (median, IQR) & $9(5-20)$ & $17(7-41)$ & $8(5-16)$ & $<0.001$ \\
\hline \multicolumn{5}{|l|}{ Outcome related variables } \\
\hline \multicolumn{5}{|l|}{ Glasgow outcome scale } \\
\hline 2 & $5(3 \%)$ & $0(0 \%)$ & $5(2 \%)$ & $<0.001$ \\
\hline 3 & $21(9 \%)$ & $7(15 \%)$ & $14(7 \%)$ & \\
\hline 4 & $52(21 \%)$ & $22(48 \%)$ & $30(15 \%)$ & \\
\hline 5 & $170(69 \%)$ & $17(37 \%)$ & $153(76 \%)$ & \\
\hline Post traumatic epilepsy & $51(21 \%)$ & $24(52 \%)$ & $29(14 \%)$ & $<0.001$ \\
\hline \multicolumn{5}{|c|}{$\begin{array}{l}\text { Abbreviations: CT, Computerized Tomography; LOS, Length of Stay; ICU, Intensive Care Unit; } \\
\text { GCS, Glasgow Coma Scale; ICP, Intracranial Pressure; TISS, Therapeutic Intervention Scoring } \\
\text { System; IQR, Inter Quartile Range; Rx, Medical Treatment; EVD, Extra ventricular drain. Values } \\
\text { are presented as the number (\%) of patients or as the median (IQR) }\end{array}$} \\
\hline
\end{tabular}


Table 2: Multivariable logistic regression including admission variables, risk of any psychotropic medication

\begin{tabular}{|lllc|}
\hline Variable & OR & $95 \%$ Cl & p-value \\
\hline Age, per year & 1.12 & $1.01-1.25$ & 0.04 \\
GCS & & & \\
$13-15$ & Ref. & & \\
$9-12$ & 0.94 & $0.34-2.60$ & 0.90 \\
$3-8$ & 1.71 & $0.71-4.12$ & 0.23 \\
Abnormal pupillary light reactivity & 1.62 & $0.62-4.22$ & 0.32 \\
Helsinki CT Score & 1.07 & $0.94-1.21$ & 0.30 \\
\hline Abbreviations: OR, Odds Ratio; Cl, Confidence Interval; GCS, Glasgow Coma Scale; CT, \\
\multicolumn{4}{l}{ Computer Tomography. The Nagelkerke R ${ }^{2}$ for the multivariable model was 0.112. } \\
\hline
\end{tabular}


Table 3: Multivariable logistic regression including all variables, risk of any psychotropic medication

\begin{tabular}{|llll|}
\hline Variable & OR & 95\% CI & p-value \\
\hline Age, per year & 1.10 & $0.98-1.24$ & 0.10 \\
GCS & & & \\
$13-15$ & Ref. & & \\
$9-12$ & 0.80 & $0.27-2.39$ & 0.69 \\
$3-8$ & 1.53 & $0.57-4.06$ & 0.40 \\
Abnormal pupillary light reactivity & 1.22 & $0.42-3.56$ & 0.72 \\
Helsinki CT Score & 1.01 & $0.88-1.17$ & 0.87 \\
Rx of AED in ICU & 2.02 & $0.80-5.10$ & 0.14 \\
ICP monitoring or EVD & 0.67 & $0.20-2.21$ & 0.51 \\
Repeated use of barbiturates & 1.02 & $0.26-4.03$ & 0.98 \\
TISS-76 average score, per point & 1.01 & $0.93-1.09$ & 0.84 \\
TISS-76 total score, per point & 0.99 & $0.98-1.00$ & 0.23 \\
LOS ICU, per day & 1.29 & $0.90-1.85$ & 0.17 \\
LOS Hospital, per day & 1.01 & $1.00-1.03$ & 0.17 \\
\hline Abbreviations: LR, Logistic Regression; OR, Odds Ratio; Cl, Confidence Interval; GCS, \\
Glasgow Coma Scale; CT, Computer Tomography; Rx, Medical treatment of; AED, Anti- \\
epileptic drug; ICU, intensive care unit; ICP, Intracranial Pressure; EVD, Extra Ventricular \\
Drain; TISS, Therapeutic Intervention Scoring System; LOS, Length of Stay. The \\
Nagelkerke R2 for the multivariable model was 0.184. \\
\hline \multicolumn{4}{l}{} \\
\hline
\end{tabular}


Table 4: Subgroup multivariable logistic regression of admission and treatment-related variables.

\begin{tabular}{|c|c|c|c|}
\hline \multicolumn{4}{|l|}{ Variables } \\
\hline Antidepressant medication & OR & $95 \% \mathrm{Cl}$ & $\mathbf{p}$ \\
\hline Age & 1.37 & $1.13-1.71$ & 0.002 \\
\hline \multicolumn{4}{|l|}{ GCS } \\
\hline $13-15$ & Ref. & & \\
\hline $9-12$ & 1.02 & $0.22-2.78$ & 0.71 \\
\hline $3-8$ & 1.02 & $0.32-3.23$ & 0.98 \\
\hline Abnormal pupillary light reactivity & 1.68 & $0.52-5.48$ & 0.39 \\
\hline Rx of $A E D$ in ICU & 1.02 & $0.36-2.90$ & 0.97 \\
\hline ICP monitoring or EVD & 0.33 & $0.08-1.32$ & 0.12 \\
\hline TISS-76 average score & 1.02 & 0.94-1.11 & 0.58 \\
\hline TISS-76 total score & 1.00 & $1.00-1.01$ & 0.38 \\
\hline LOS ICU & 0.94 & $0.75-1.17$ & 0.56 \\
\hline LOS Hospital & 1.02 & $1.00-1.04$ & 0.06 \\
\hline \multicolumn{4}{|l|}{ Stimulant medication } \\
\hline Age & 0.78 & $0.64-0.95$ & 0.01 \\
\hline Gender & NA & & \\
\hline Rx of AED in ICU & 1.93 & $0.31-12.01$ & 0.48 \\
\hline ICP monitoring or EVD & 4.50 & $0.24-85.37$ & 0.32 \\
\hline TISS-76 average score & 0.99 & $0.83-1.18$ & 0.88 \\
\hline TISS-76 total score & 0.99 & $0.98-1.00$ & 0.23 \\
\hline LOS ICU & 1.29 & $0.90-1.85$ & 0.17 \\
\hline LOS Hospital & 1.01 & $1.00-1.03$ & 0.17 \\
\hline \multicolumn{4}{|l|}{ Antipsychotic medication } \\
\hline Age & 1.24 & $1.00-1.52$ & 0.05 \\
\hline Helsinki CT Score & 1.15 & $0.98-1.34$ & 0.09 \\
\hline \multicolumn{4}{|c|}{$\begin{array}{l}\text { Abbreviations: LR, Logistic Regression; OR, Odds Ratio; Cl, Confidence Interval; GCS, Glasgow Coma } \\
\text { Scale; CT, Computer Tomography; Rx, Medical treatment of; AED, Anti-epileptic drug; ICU, intensive care } \\
\text { unit; ICP, Intracranial Pressure; EVD, Extra Ventricular Drain; TISS, Therapeutic Intervention Scoring } \\
\text { System; LOS, Length of Stay. The Nagelkerke R2 for the antidepressant model was } 0.184 \text {. The } \\
\text { Nagelkerke R2 for the stimulant medication model was } 0.363 \text {. The Nagelkerke R2 for the } \\
\text { antidepressant model was } 0.096 \text {. }\end{array}$} \\
\hline
\end{tabular}


Table 5: Psychotropic medication frequencies in patients categorized by age groups and Glasgow Outcome Scale

\begin{tabular}{|c|c|c|c|c|}
\hline $\begin{array}{l}\text { Age 5-11 years } \\
(\mathrm{N}=78)\end{array}$ & $\begin{array}{l}\text { Any } \\
\text { psychotropic } \\
\text { medication } \\
(n=8)\end{array}$ & $\begin{array}{l}\text { Antidepressant } \\
\text { medication } \\
(n=2)\end{array}$ & $\begin{array}{l}\text { Stimulant } \\
\text { medication } \\
(n=5)\end{array}$ & $\begin{array}{l}\text { Antipsychotic } \\
\text { medication } \\
(n=2)\end{array}$ \\
\hline $\begin{aligned} \text { GOS } 2(n=0) \\
3(n=5) \\
4(n=10) \\
5(n=63)\end{aligned}$ & $\begin{array}{l}\text { NA } \\
2(40 \%) \\
3(30 \%) \\
3(5 \%)\end{array}$ & $\begin{array}{l}\text { NA } \\
0(0 \%) \\
1(10 \%) \\
1(2 \%)\end{array}$ & $\begin{array}{l}\text { NA } \\
1(20 \%) \\
3(30 \%) \\
1(2 \%)\end{array}$ & $\begin{array}{l}\text { NA } \\
1(20 \%) \\
0(0 \%) \\
1(2 \%)\end{array}$ \\
\hline $\begin{array}{l}\text { Age 12-17 years } \\
(n=170)\end{array}$ & $(n=38)$ & $(n=31)$ & $(n=4)$ & $(n=15)$ \\
\hline $\begin{aligned} \text { GOS } 2(n=5) \\
3(n=16) \\
4(n=42) \\
5(n=107)\end{aligned}$ & $\begin{array}{l}0(0 \%) \\
5(31 \%) \\
19(45 \%) \\
14(13 \%)\end{array}$ & $\begin{array}{l}0(0 \%) \\
4(25 \%) \\
15(36 \%) \\
12(11 \%)\end{array}$ & $\begin{array}{l}0(0 \%) \\
0(0 \%) \\
1(2 \%) \\
3(3 \%)\end{array}$ & $\begin{array}{l}0(0 \%) \\
2(13 \%) \\
10(24 \%) \\
3(3 \%)\end{array}$ \\
\hline
\end{tabular}




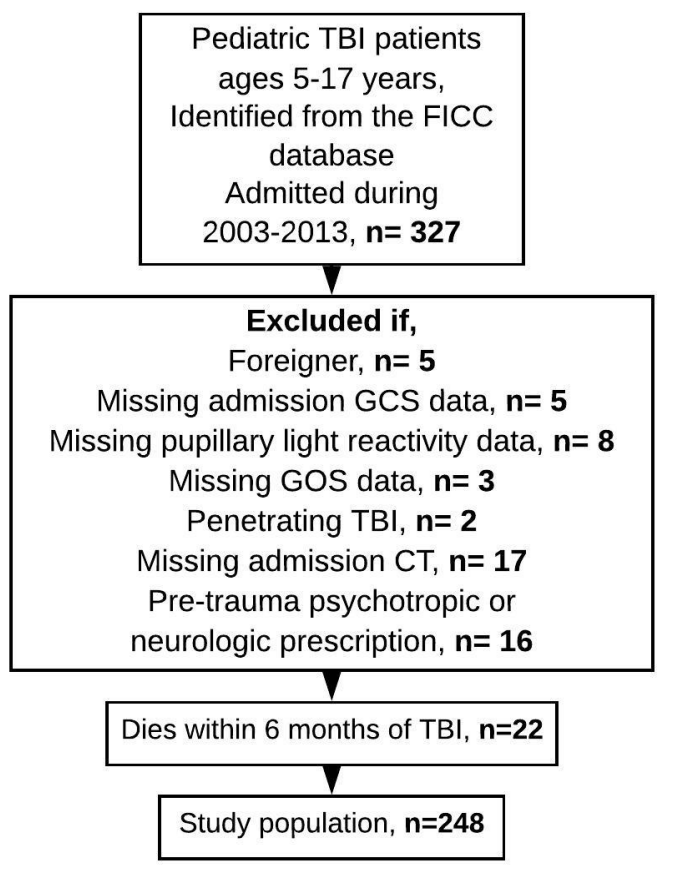

